\title{
A Model to Represent the Facets of Learning Objects
}

\author{
Nathalie Hernandez \\ Institut de Recherche en \\ Informatique de Toulouse, \\ Toulouse, France \\ hernandez@irit.fr
}

\author{
Bertin Ramamonjisoa \\ Université de Fianarantsoa, \\ Ecole Nationale d'informatique, \\ Madagascar \\ bertin@mail.univ-fianar.mg
}

\author{
Josiane Mothe and \\ Bachelin Ralalason \\ Institut de Recherche en \\ Informatique de Toulouse and \\ ERT34, Institut Universitaire de \\ Formation des Maîtres, \\ Toulouse, France
}

mothe@irit.fr bachelin@irit.fr

\author{
Patricia Stolf \\ Institut de Recherche en \\ Informatique de Toulouse and \\ ERT34, Institut Universitaire de \\ Formation des Maîtres, \\ Toulouse, France
}

\section{stolf@irit.fr}

\begin{abstract}
This paper presents a model to describe Learning Objects (LO). The main objective of this model is to consider all the aspects of the LO for which a description will ease LO re-use. The LO description we promote complies with the current standards of e-learning and includes the following: metadata, scenarios the objects are used in, and the objects they are composed of. We enrich this multi-facet representation by taking into account the semantics of learning object contents. Another contribution of our work is that this multi-facet representation relies on ontologies, allowing a semantic representation that facilitates communication between machines and users.
\end{abstract}

Keywords: e-learning, reuse of learning objects, standards for e-learning, ontologies, semantic representation.

Material published as part of this publication, either on-line or in print, is copyrighted by the Informing Science Institute. Permission to make digital or paper copy of part or all of these works for personal or classroom use is granted without fee provided that the copies are not made or distributed for profit or commercial advantage AND that copies 1) bear this notice in full and 2) give the full citation on the first page. It is permissible to abstract these works so long as credit is given. To copy in all other cases or to republish or to post on a server or to redistribute to lists requires specific permission and payment of a fee. Contact Publisher@,InformingScience.org to request redistribution permission.

\section{Introduction}

E-learning relies on the provision of electronic documents, called learning objects, organized in teaching scenarios.

Many digital pedagogical resources can be found on the web but they are often on-line presentations of existing documents and, thus, not designed to be included in e-learning platforms. Psyché, 
Bourdeau, Nkambou, and Mizoguchi (2005) note that more pedagogical approaches and learning designs should be proposed to improve the use of resources in e-learning systems. In addition, learning objects should be reusable in different teaching scenarios. E-learning technologies and standardization efforts offer a partial solution to these issues. SCORM (2004), Fage (2005), and LOM (2002) contribute to the homogenization of learning object representations and facilitate their interworking, while IMS-LD (IMS Global Learning Consortium, 2003) considers the pedagogy of training and its progress. However, the metadata associated with objects are limited and do not focus on content. It is then difficult for a designer to know if a resource (image, chunk of text, exercise, concept definition, etc.) already existing in a document can be re-used. As a result reusability is low.

Our contribution in this paper is related to the enrichment of e-learning standards with the representation of complementary knowledge that would be helpful for a user to know, specifically about the content of a learning object. This knowledge is represented in the form of ontologies (Mizoguchi, 2004). This additional knowledge corresponds, on one hand, to the theme studied, that is to say the topic of the course, and, on the other hand, to the pedagogical theories.

In this paper, we present first the main e-learning systems' characteristics and standards. Then we describe the conceptual model we promote to represent learning objects and their usages. Next, we explain the implementation, and, finally, we give a short example of an instance based on our model.

\section{State of the Art}

\section{E-learning Systems: Learning Objects and Standards}

E-learning is a teaching-learning activity which aims at knowledge acquisition while reducing the time and space constraints between learners and teachers, thanks to new communication and information technologies (Boutmedjet, 2004; E-TUD, n.d.).

An e-learning system must allow:

- $\quad$ access to the relevant learning objects thanks to a relevant indexing of the resources (Abel, Lenne, Moulin, \& Benayache, 2003; Gasevic and Hatala, 2005; Lenne, Abel, Moulin, \& Benayache, 2005; Psyché et al., 2005)

- browsing techniques improving learner / teacher / system interactions according to an adequate pedagogy (Psyché et al., 2005),

- reusability of learning objects and learning design (Knight, Gasevic, \& Richards, 2005),

- $\quad$ design and update of the contents of courses by teachers, (Abel et al., 2003; Lenne et al., 2005),

- $\quad$ an individualized monitoring of learners (IMS Global Learning Consortium, 2003).

A learning object has been defined by the IEEE-LTSC working group (Learning Technology Committee Standards) as, "Any entity, digital or non-digital, which can be used, reused or referenced during technology supported learning" (Hodgins, 2008).

Various standards have been defined to help the development of training systems. Friesen (2005) presents an overview of e-learning standards, the goal of which is to ensure interoperability, portability, and reusability. These systems handle learning objects, their representation, and their relationship. The use of these standards, which are considered as common description languages of digital educational resources (Vidal, Broisin, Duval, \& Ternier, 2004), guarantees not only the 
interworking but also the quality of systems to facilitate the usage of the learning objects no matter the platform or the technological environment used.

The standards are mainly used to ensure:

- Interoperability: towards the content exchanged and handled by different systems and the interaction between learning management systems.

- Re-use: not only towards the rapid assembly of contents and codes but also the assembly and objects use in new contexts.

- Adaptability: the system can be configured to have extended functionality for new goals.

- Durability: ability to use learning objects in any educational context, to adapt to changes in the runtime environment, and to provide for lasting use of these resources

Among e-learning standards, LOM, SCORM and IMS-LD are the most important. LOM focuses on describing resources (objects), SCORM on the structure of objects, and IMS-LD on the teaching scenario.

\section{LOM}

LOM (2002) (Learning Object Metadata) is a standard for learning object annotation with metadata. It specifies the syntax and semantics of the metadata describing educational digital or nondigital resources and defines the attributes necessary for a complete description of the educational resources. Metadata are classified into nine categories as follow:

1. General: characteristics that are independent from the context, such as the identifier, the title, the language of the resource, etc.

2. Lifecycle: groups the features related to the history (Version) and current state (Draft, Final, Revised, Unavailable) of this learning object and those who have affected this learning object during its evolution.

3. Meta-metadata: characteristics of the description, such as Identifier, Contribution (persons having participated in the elaboration of the metadata), Catalog, language, etc.

4. Technical: technical requirements and technical characteristics, such as the format (of the necessary software to reach the resource), size of the learning object, etc.

5. Educational: groups the educational and pedagogic characteristics of the learning object.

6. Rights: the intellectual property rights and conditions of use for the learning object; Costs, copyrights, description.

7. Relation: defines the relationship between a learning object and other related ones.

8. Annotation: provides comments on the educational use of the learning object and provides also information on the author and the date on which comments were created.

9. Classification: describes the learning object in relation to a particular classification system, such as purpose, reference classification, path, etc.

LOM standardizes indexing of learning objects in e-learning systems by giving specific information on the object.

Nevertheless, most of the participants in the standardization make some criticisms about LOM (Bourda, 2001; DeLa Passardière \& Jarraud, 2004):

- Some inconsistency between the generic definition of learning objects as proposed by IEEE and the elements to describe them, due to the consideration of non-digital entities. 
- The fact that the indexing unit is a file, which represents a technical unit but not an educational one;

- The fact that a complete lesson is indexed in the same way as a unique exercise or an image;

- $\quad$ The fact that some ambiguities remains in metadata;

- The ambiguities in the model make difficult its usage.

To solve these problems, they propose using LOM application profiles. In an application profile, the mandatory elements provide a minimum of information for a given resource while the optional ones simplify the indexing. An application profile is an instance of a model, as LOM, in a particular context; it is composed of a metadata subset adapted to the needs of the groups or of a particular application, while remaining interoperable with the original LOM schema.

To achieve this, the syntax and the semantics of the LOM are interpreted, refined, spread, and simplified.

LOM standard and application profiles are useful to assure access to pedagogical resources. However, they do not specify the semantic content of resources. For this reason, we complete a LOM description with a content representation based on theme ontology.

\section{SCORM}

SCORM (Sharable Content Object Reference Model) (SCORM, 2004) of Advanced Distributed Learning (ADL) is a suite of technical standards that enable web-based learning systems to find, import, share, reuse, and export learning content in a standardized way.

SCORM treats the following elements:

- Packaging: It has for its objective the transmission of contents between platforms and handling the structure the educational objects.

A SCORM package is a ZIP file which contains :

○ Elements under varied formats (HTML, JPEG, Flash Animations, Word, PPT...)

- A Manifest (XML file) containing :

- a metadata section which describes the package,

- a section of resources which lists elements in the archives and the available resources via an URL on Web,

- a section of organization which describes the structure of the resources.

- Metadata: they came from LOM and their objective is to share the standard information which describes the nature and the objective of the contents. This information can be used either for helping object searching or for managing the users' rights and for technical needs.

- Communication or environment of execution: determines the communication with a Web environment. The notion of environment is also present in IMS-LD.

- Sequence and browsing: defines a method of representation for browsing the learning objects. Specifically, it describes connections and streams of learning activities in terms of trees of activity.

- Content Aggregation: it distinguishes three levels of resources:

- The elementary digital resource (Assets) establishes the basic elements of learning resource; it can involve a simple document (JPEG image or GIF, WAV sound 
or MP3, web page) but also any set of information which can be released to a Web client (Flash document, Javascript code, etc.).

- A Shareable Content Object (SCO) is a coherent set of Assets. Respecting the SCORM protocol of execution, it represents the lowest level of resource granularity.

- A Content Aggregation is a set of educational resources structured in a coherent way within an entity of higher level, such as a lesson, a chapter, a module, etc.

The structure of the contents of the course modules according to the SCORM model allows them to be reused in others modules for various training formations or systems. Furthermore, it improves the dialogue between the learning objects and the system on one hand, and between the actors and the system on the other hand.

SCORM defines what the mandatory characteristics of learning objects are as follows:

- Reusability: the contents are independent of the context of learning and can be used by several learners.

- Accessibility: the contents can be identified and located at any time.

- Interoperability: the contents can be read and used in any environments (Hardware and software)

- Durability: the contents do not require modification further to a change or an update of the operating system.

In addition, the learner's progress is supervised and reported back. In our model, SCORM is used to represent learning resource structure and to insure interoperability.

\section{IMS-LD}

A Learning Design is a description of a method allowing to a learner to reach some objectives by the performance of some ordered educational activities in a learning environment (IMS Global Learning Consortium, 2003). As a supplement to SCORM, IMS-LD (Instructional Management System Learning Design) is a standard which aims at bringing elements of pedagogy into an elearning system. It is a language to model learning process. Based on the work of Koper (2001), it is designed to define learning scenarios and interaction for content creators. It helps the designers to model the teaching scenario organization like: "who makes what, when, and with which resources and which services to realize objectives of learning?"

The IMS-LD standard aims at helping to design any teaching-learning process in a formal way. It structures learning units through play, act, and role-part elements. The play element (that is often unique) contains several act elements. These acts are run in sequence; each one being triggered by the end of the preceding one. The play is complete when the last act is finished. The transitions between acts thus form a set of synchronization points for all the participating roles (teacher, learner...).

In order to facilitate the production and its implementation, LD has been divided into three levels:

- Level-A: contains all the basic structures including: Activities, Environment, Components, Proceedings, Roles, Services,

- Level-B: adds Properties and Conditions to A. This allows more advanced customization, sequencing, and interaction based on the profile of each learner, 
- Level-C: adds the notifications to level B. A notification is triggered by the completion of a result and makes an activity available and executable for a given Role. Each level is represented by separated XML files.

In the proposed model, IMS-LD is used to define interaction between learners and computers during the phase of execution and use of the learning objects.

These standards solve several problems, such as interoperability and use in pedagogical scenarios, but for Varlamis and Apostolakis (2006), to achieve better co-operation between e-learning components it is important to define standards which cover all the e-learning process. However, reuse and access (how to find the most relevant resources) are not solved. Another problem is how to assign the same meaning to given metadata. Finally, the links and relations, such as the content, sequencing, and dependence of prerequisites between every learning object, must be mentioned to allow the system to effect treatment or automatic tasks on these objects.

Before describing the model, we present related works that try to enrich learning object representation using ontologies.

\section{Ontology-based E-learning Systems}

Using metadata as recommended by e-learning standards is not sufficient to solve the problems of object reusability and accessibility (Zarraonandía, Dodero, Díaz, \& Sarasa, 2004). Indeed, these problems will be solved only if a common meaning for metadata values is used by the system and the actors. On the other hand, bonds and relations such as content, sequencing, and dependence of pre-knowledge between learning objects must be included to make it possible, not only to carry out automatic treatment or tasks on these objects, but also to produce new knowledge from what already exists. The use of ontologies in the model of an e-learning system is an interesting solution. An ontology gathers the concepts which represent the knowledge of a field in an explicit and formal specification (Studer, Benjamins, \& Fensel, 1998). Snae and Brueckner (2007) present an ontology for the e-learning process: from the construction of e-learning objects to the administration tasks. They propose ontologies to describe the semantics of the process, but also the activities, the communication, and the context of e-learning. MEMORAE "MEMoire ORganisationnelle Appliquée à l'e-learning" (Organisational Memory Applied to e-learning) (Abel et al., 2003; Lenne et al., 2005) is an e-learning tool which allows resource indexing. This tool provides learners with educational resources, either within a local resource repository or on the web. Compared to MEMORAE, which presents courses structured according to the relations of inclusion, usage, reference, and prerequisite between the concepts to be learnt, Gasevic and Hatala (2005) allow the users to formulate queries. Moreover, they respect the LOM standard. These two studies represent the system knowledge through ontologies. An ontology describing the concepts such as the people (students, tutors, secretaries...) and the documents (books, presentation slides, web pages...) is called ontology of the training field for Lenne et al. (2005) and target ontology for Gasevic and Hatala (2005). Mitrovic and Devedzic (2002) also use an ontology to represent the domain of each tutor. Another ontology is used to represent the concepts to be learnt (ontology of application for Lenne et al., 2005 and source ontology for Gasevic and Hatala, 2005). In order to ensure reusability, Hernandez (2005) advises separating task (learning context, documents...) and theme (concepts to learn) in the application.

Psyché et al. (2005) and Knight, Gasevic, and Richards (2005) integrate the notion of teaching scenarios using an ontology based on the standard IMS-LD. Psyché et al. only take into account the educational theories. As in Lenne et al. (2005) and Hernandez (2005), Renaud, Vignaux, and Tijus (2006) and Bouzeghoub, Defude, Duitama, and Lecocq (2005) use an "ontology of theme" which represents all the concepts describing the domain knowledge to semantically index resources. However Bouzeghoub et al. (2005) is characterized by the use of two types of metadata: one for describing the pedagogical aspects and the other for the semantic aspects of the resources. 
In the studies of Gasevic and Hatala (2005), Lenne et al. (2005) and Psyché et al. (2005), the real context of learning object use is not taken into account. In order to increase the reusability of scenarios and learning objects, Knight et al. (2005) introduce an "ontology of context".

To obtain all the qualities required for an e-learning tool, like reusability, accessibility, interoperability, and durability (Fage, 2005; SCORM, 2004), we take into account learning theories as well as the contexts of training and uses of learning objects. Our approach is based on ontologies as well as on the e-learning standards. This paper focuses on the aspects corresponding to the representation of learning objects and their uses.

\section{Semantic Representation Model and Use of Learning Objects}

\section{Multi-facet Representation and Usage of Learning Objects}

The model we promote takes into account the various aspects of learning objects. Our model includes technical description and pedagogical description and also related uses of the learning objects. This model allows building a system that relies on an appropriate pedagogical approach. It also enables the reuse of learning objects and learning design.

To represent a learning object we consider various items of knowledge:

- Knowledge about the structure (standard SCORM), and about the resource itself (standard LOM),

- Knowledge about the theme: notions to learn,

- Knowledge about educational theories,

- Knowledge about learning design (IMS-LD standard).

Figure 1 represents the 4 different facets used in our representation of a learning object. These aspects of a learning object are described in the following sections.

\section{SCORM and LOM description}

A learning object is a semantic unit of an educational resource. It can be an exercise, an examination question, a definition, examples, a lesson, etc. Each learning object can gather elementary components (such as an image) named Component (called "As-

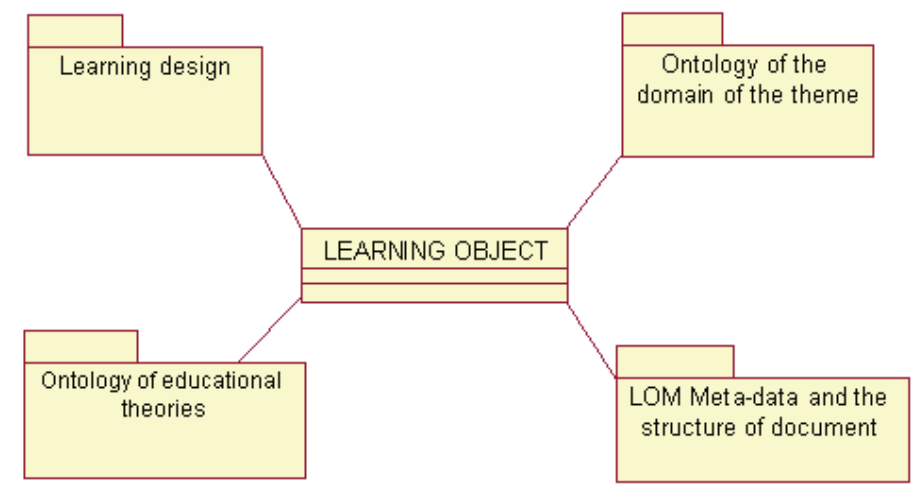

Figure 1: Useful knowledge to represent a learning object and its use sets" in SCORM standard) which can be in different digital (.DOC, .PDF, .JPG etc) or physical formats.

The description of the metadata associated with a pedagogical document corresponds to LOM description. As in Duval, Sutton, and Weibel (2002), we propose the use of a Profile of application in order to indicate what is mandatory and optional as metadata for an object. In our proposal, a LOM description is attached to 
each learning object (elementary or composed object). The useful metadata for a given application is filtered via the application profile.

The metadata we consider for representing a learning object are presented in Figure 2. A Learning Object can be composed of other Learning Objects. A learning object is a LOM Object and consists of SCORM Assets. As proposed in LOM, the object is annotated with different Ele-

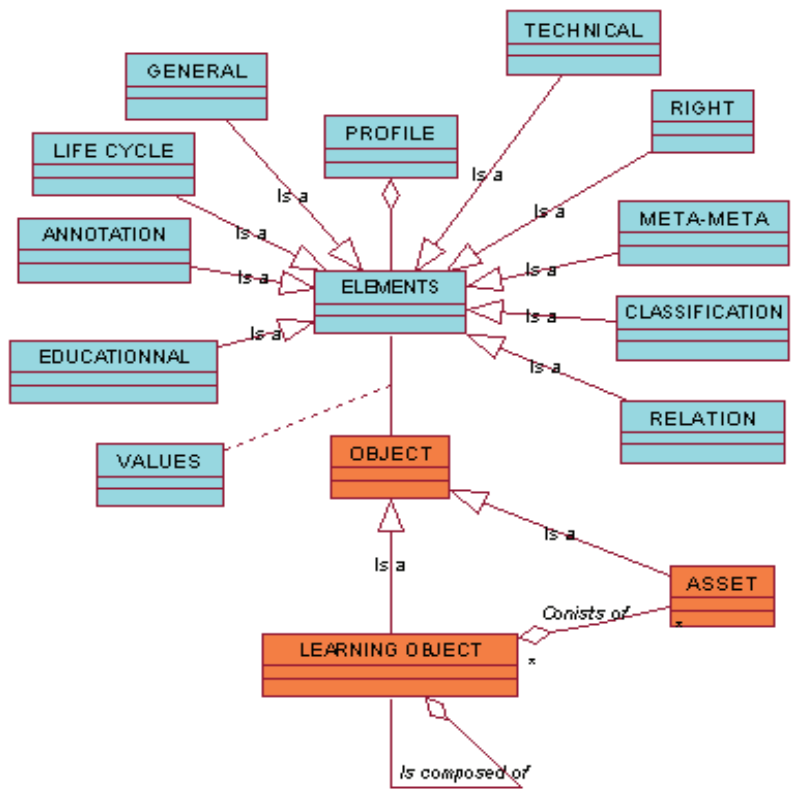

Figure 2: SCORM and LOM descriptions ments or metadata, such as the Right associated to the object, Technical (the technical requirements and technical characteristics of the object), Educational (the educational and pedagogic characteristics of the learning object), etc. (See the section on LOM for more details). All metadata can be filtered according to a Profile.

When an object is used in a given course, some values of metadata associated with the course itself are automatically filled in for the associated learning objects.

Modeling this information does not require the use of an ontology. Hence, this description is not based on an ontology but rather on simple metadata associated to objects.

However, as indicated above, the semantic representation of object contents proposed in current e-learning standards is not sufficient to allow their complete or partial reuse in other applications or other systems. We, therefore, supplement it by a thematic representation of contents.

\section{Thematic description}

Learning objects are also represented according to the themes or concepts they deal with. Learning objects are indexed with concepts of a theme ontology describing the notions associated with the considered domain. As presented in Figure 3, a theme ontology relies on a specific model. This model enables representation of the different Modules that will be given for a Formation and the Notions that will have to be taught to the learners for each Module. For example, in a

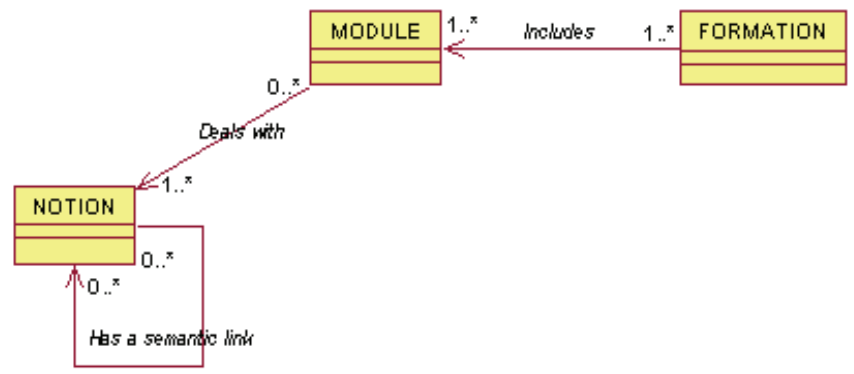

Figure 3: Thematic description computer science formation, a module will be given on databases. Examples of notions to be taught are relational database, which is conceptualized by an Entity-Relationship model. These notions, theme, and knowledge to be learnt are gathered in an ontology.

To represent the semantics of learning object contents, concepts from the theme ontology are associated with them. In other words, 
for a given module, the concepts to be learnt are specified in a theme ontology and learning objects related to this domain are indexed using these concepts.

This approach has various advantages for teachers as well as for learners. Indeed, when a teacher wishes to create a lesson, he can have access to the set of learning objects which were indexed by a specific concept. A teacher can then reuse these retrieved objects or decide to design new ones if they are not appropriate.

\section{Educational theory description}

According to educational theories, each pedagogy belongs to a specific approach (Empiricist, Rationalist, Interactionist) (Lebrun, 2002) and consists of several distinct stages to follow. A given pedagogy will give place to several teaching scenarios (Methods).

A Stage indicates the theoretical structure of a given teaching approach, as illustrated in Figure 4.

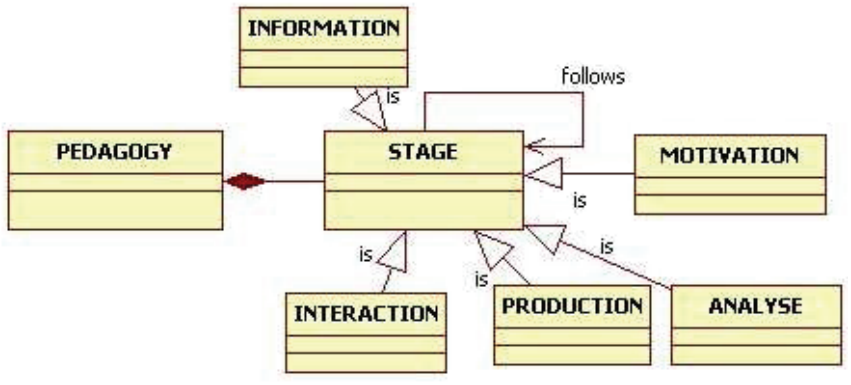

Figure 4: Educational theory description It can be a phase of information, motivation, interaction, production, analysis, etc. Pedagogy describes the set of educational theories which can be used for carrying out trainings successfully.

Knowledge associated with teaching theories is represented through an ontology. This representation is justified by the fact that we wish to be able to consider reasoning as well. More specifically, it would then be possible to

guide the construction of a scenario starting from a learning object and using knowledge from educational theory. This representation is inspired from EML-OUNL (Koper, 2001).

\section{Learning design description}

IMS-LD proposes to model the sequencing of activities allotted to each role to attain the goal of the course while following a well defined pedagogy. Knowledge that must be taken into account is of various types as follows:

- Knowledge about actors involved in the course (learner, teacher ...). It is represented by the Role. Each role has some activities.

- Knowledge about scenarios in which learning objects are used. It is called Method; it can be composed of plays. A play is composed of acts which are composed of role-parts. A role-part associates a role with an activity.

- Knowledge about the activities in which a learning object is used. In our model, Activity describes the tasks a learner performs (exercise, lecture...).

- Knowledge about the context in which a learning design is used. A learning object may be used differently in different activities. The context makes it possible to describe the use of a given learning object in an activity.

All this knowledge is represented thanks to an ontology, as shown in Figure 5. 


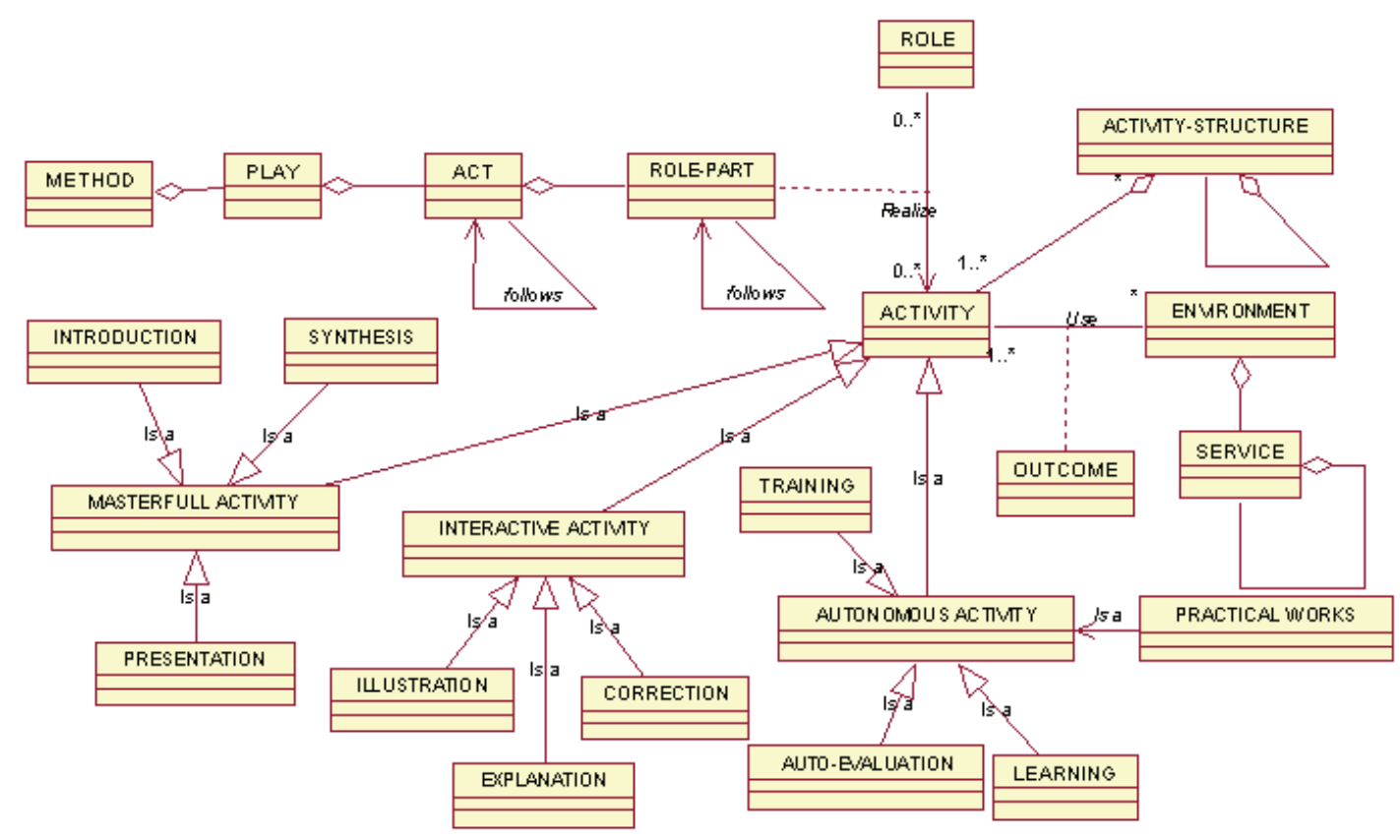

Figure 5: Description of a teaching scenario (Learning design).

\section{The Global Model}

The different facets we detail in the previous section are integrated in a single model described in Figure 6. Concept interlinks are introduced. The various activities of the lessons and their organization, as well as the learning objects used, are represented by the link between Activity and Learning object classes. The use of an object in various activities is specified in the Context class. The prerequisites for activities are considered through the prerequisite notions (concepts from the theme ontology) and prerequisite competences. This corresponds to a relationship between Activity and Notion. The concept Pedagogy of the educational theories ontology is linked to the concept Method of the learning design ontology. So, according to the chosen educational theory, a teacher can be helped while constructing a resource. The concept Notion of the theme ontology is linked to the concept of Activity because learning a notion can be carried out in different activities. The same object can be used for several Notions and in several Activities.

By using these four facets (as summarized in Figure 1) the suggested model improves reusability of an object. Its description by metadata and especially about its content, as well as the definition of its structure, makes it possible to implement mechanisms for accessing and searching learning objects and elementary components. Object use in scenarios of training also can help a designer to understand better a learning object and help her to consider it as a component of a new course. Lastly, the interoperability and durability are ensured thanks to the conformity of the model with the standards. 


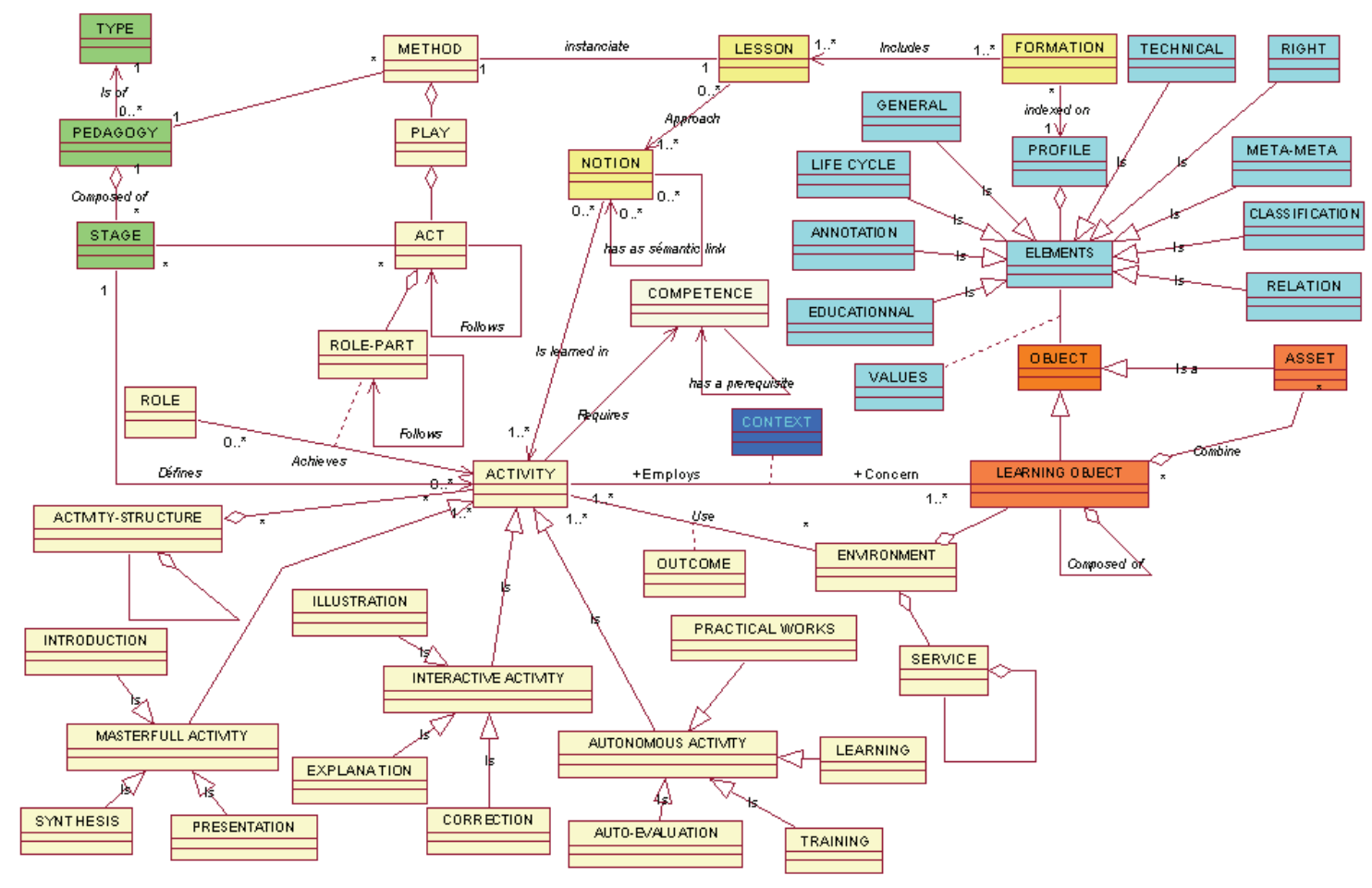

Figure 6: Complete model integrating the various aspects of representation of a learning object in its context of use.

\section{Implementation}

We implement the ideas that are presented through the model using the Reload CP Editor; we also used the Protégé software. We based this first stage of validation on courses from the etraining e-MIAGE (Méthodes Informatiques Appliquées à la Gestion des Entreprises) from the Université de Toulouse III (www.e-miage.org). Some of the elements we present here are extracts from the classes on relational databases in L3 level. Then, from these learning objects, we consider how to implement our model to make it usable.

\section{Ontologies}

Ontologies are implemented using OWL (Web Ontology Language) (W3C, 2004) using the Protégé resource (Stanford Medical Informatics, 2007). Regarding the domain ontologies, they are manually built (meaning that we choose the concepts to include). However, we have also developed a method that helps a designer to build ontologies based on texts on the domain (AussenacGilles, Biébow, \& Szulman, 2000; Mothe \& Hernandez, 2007).

\section{LOM and Application Profile}

Parameters from Reload CP Editor have been set in order to take into account the application profile. For doing this we modify two files: the profile file and vocabulary file.

The application profile we defined is composed of the LOM enriched by the vocabulary associated with the "Learning object type » metadata which considers pedagogical functions. This metadata implements the link between the ontology of the educational theories and learning objects. 
The metadata we added is the « Notion » which takes its values from the domain ontology. Thus, this metadata implements the link between the domain ontology and learning objects.

Both the "Learning object type » and the «Notion » are defined as mandatory in the application profile. Figure 7 is an extract of the application profile vocabulary description.

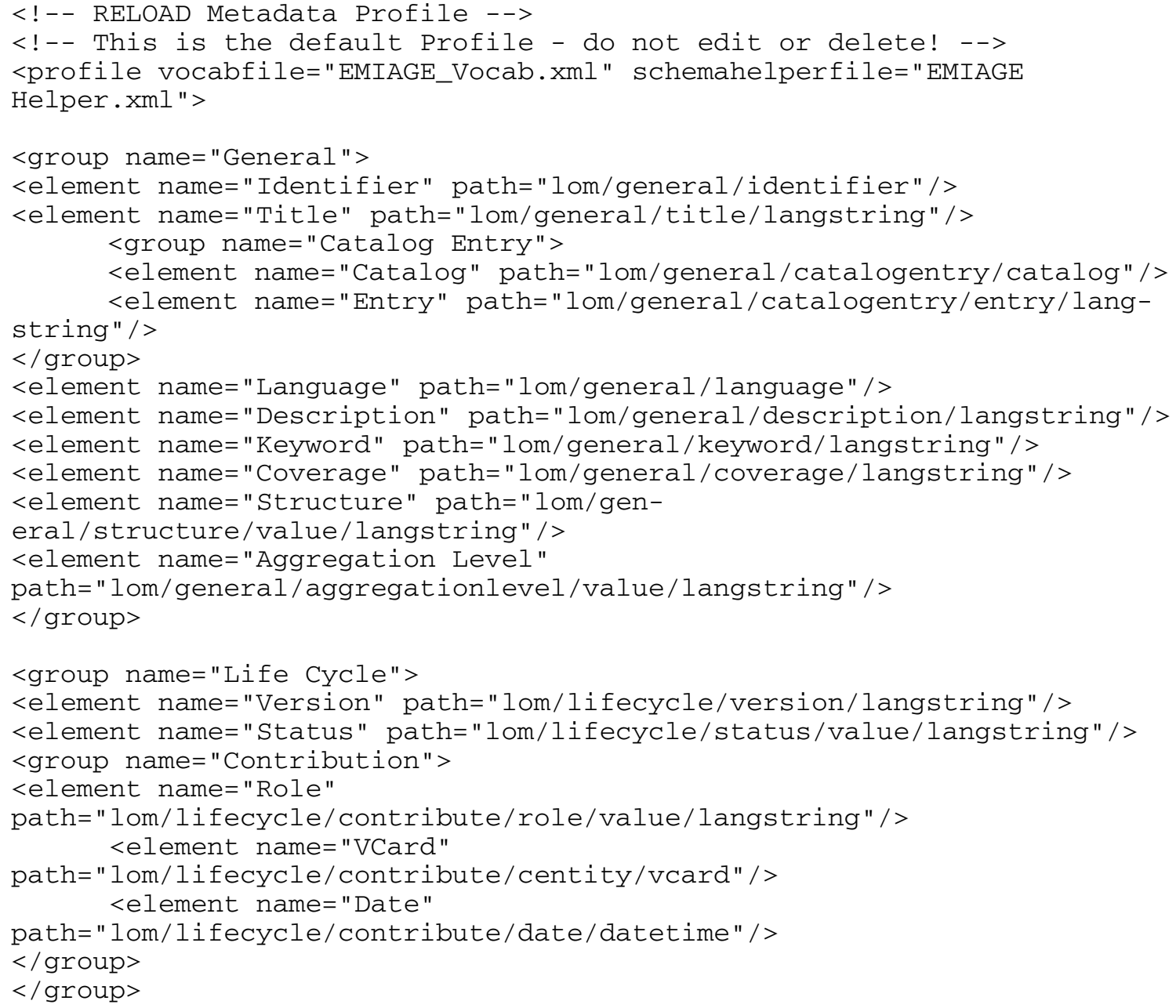

Figure 7: Extract of file profile EMIAGEProfile.xml

\section{Thematic Description of Learning Objects}

With regard to the thematic description of learning objects, in addition to ontologies we need a process to make the link between the domain ontology and the learning objects. This link is made by automatically indexing the learning objects by the concepts of the domain ontology. To implement this, we will reuse the modules developed by our team in Hernandez (2005). This work proposes methods for automatically extracting from document contents the concepts of a domain represented by an OWL ontology. This work can be used to index the learning objects as documents. According to this approach, the semantic indexing is composed of two stages: identification of the concepts in the objects and weighting these concepts in order to determine their representativeness of the objects. To automatically extract the terms from the contents, we use a syntactic text parser, in our case Syntex (Bourigault \& Fabre, 2000), itself based on TreeTagger POS. Syntex extracts the text units from each document and marks them up as noun phrases, verbs, etc. 
We then consider noun phrases only because they correspond to the nature of the concept labels in a domain ontology, and in order to capture the lexical variations of the phrases, these noun phrases are translated into their lemmatized ${ }^{1}$ form (Syntex and TreeTagger do this for us). Finally, the lexicon of a document is defined by the set of the extracted and lemmatized noun phrases. The phase of identification of the concepts that occur in a document consists of finding the labels of the ontology as well as the corresponding concepts among the extracted phrases composing the document lexicon. The following stage consists in assigning weight to the extracted concepts. The concept weight aims at determining the degree to which this concept is representative of a given document, but also reflects its capacity to distinguish the relevant documents from those which are non-relevant when this concept is used in a query. This degree is called statistical representativeness of the concept. We use a concept weighting which takes into account both the statistical representativeness and the semantic representativeness of the concept. The statistical representativeness is calculated by the adaptation of the tf.idf measure (Robertson and Spark Jones, 1976) used in information retrieval. This function takes into account the fact that the more a term occurs in a document, the more it should represent it (tf); and that the more the number of documents a term occurs in, the less the term should represent a document content (idf). Applied to the learning objects, this concept weighting will make it possible to index the contents automatically. However, the indexing by the other ontologies or representations (LOM, SCORM, and learning design descriptions) will remain manual. Thus, the teacher or designer who created a new learning object will have to fill out these descriptions.

\section{Scenario}

Finally, regarding the implementation of scenario, we used Reload Learning Design Editor. This editor uses IMS-LD standard. Once produced, the learning units can be interpreted by LD Players.

\section{Illustration within the Framework of a Course}

In this section, we illustrate our model using a simple example (case study) on a course on computer science (database lesson). We consider a learning object which is an exercise on data file indexing. The object is composed of three elementary objects: two images of B-trees in jpg and an examination statement.

We illustrate in the following subsections how our model allows the learning object to be reused according to various pedagogical purposes.

\section{Learning Objects Reuse According to LOM}

The learning object exercise and each of its elementary elements are annotated using LOM and according to the model presented in Figure 2. These metadata help the learning system users reuse the different elements easily.

For example, considering the two images, the Right element from LOM is defined by its authors as Public metadata, so any teacher or learner may reach it and use it. On the other hand, for the Examination statement and the Exercise, the Right metadata element is defined as Private to the people following the course. This implies that the examination statement as well as the learning object exercise can be reused only by teachers of the course and be accessed by learners registered in this course. Teachers can thus reuse the exercise in other lessons, while students can only reuse the B-trees images for making revision notes.

1 Lemma : A canonical form of a term, particularly in the context of highly inflected languages. AllWord Dictionnary (http://www.allwords.com/word-lemma.html) 
The metadata pedagogy-level related to the exercise is set at initiation. This indicates that the exercise is addressed to students who have not studied file indexing methods. The exercise can be used by teachers for designing any module addressed to a public having this level.

\section{Learning Objects Reuse According to their Content}

Learning objects are also represented by the concepts that they are dealing with. An extract of the ontology of the theme of data processing is presented in Figure 8.

This extract corresponds to the ontology related to the database domain. The concepts are represented by rectangles containing the various labels or terms, the captioned arrows represent the semantic relations between concepts. In the extract presented here, the doubly-framed concepts represent the concepts to be studied within the framework of the module "Relational Data Base".

One of the images represents a "B-tree +", and the other a "B-tree *". In our model, the two images are thus represented by these two concepts of the ontology of data processing. Suppose, the exercise approaches the concepts of "indexed organization" of the data, starting from "B-trees" while insisting on the "access time" to the base. These three concepts of the ontology are then used to index it. The advantage of specifying these concepts is that a teacher will be able to reuse this exercise when s/he wants to work on the concepts previously quoted. Moreover, as the notions are represented within an ontology, different teachers can interpret the same meaning associated to the notions by visualizing the different concepts and relations stated in the ontology.

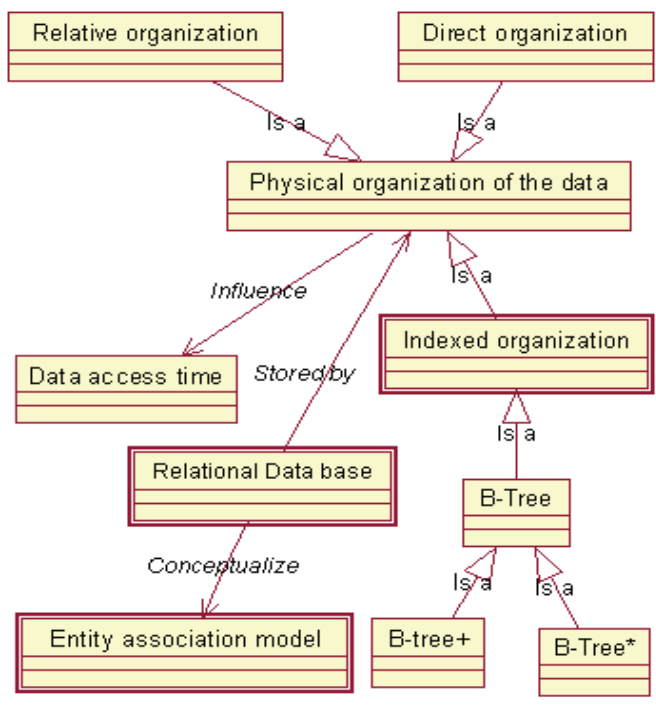

Figure 8: Extract of the theme ontology of the data processing.

\section{Learning Design}

Learning scenarios are also considered in our model. Learning objects are represented according to the acts and plays in which they have already been used. Let us consider the following scenario composed of different acts.

Act 1: The teacher presents the notions to be studied by students by providing a written document.

Act 2: The students read the corresponding resource and require explanations from the teacher.

Act 3: The teacher gives explanations, using examples, and waits for a new reaction of the students. Possibly s/he gives additional explanations if the students request some.

Act 4: When the time limit is reached, the teacher gives the exercises which the students must do.

Act 5: The teacher corrects the exercises while providing precise explanations on each point that is not mastered by the student, by e-mail, by on-line dialogue, or on a forum. In order to ensure the comprehension and memorization of the concepts to be learnt, self-assessment and some exercises to evaluate the students are provided to them.

Act 6: Finally, the teacher gives a summary of the most important points on the studied notions.

When this scenario is chosen, the system will be able to propose our learning object "exercise" and its elementary elements for different acts. The exercise can be used in both Acts 4 and 5 . 
Hernandez, Mothe, Ralalason, Ramamonjisoa, \& Stolf

When preparing these two acts, the teacher will have access to all the exercises that have been indexed with the notions considered and that have already been used in such kind of acts. The images of the B-tree + and B-tree * can be proposed during Act 1 to help the teacher design the written document, in Act 3 to help the teacher give examples, and in Acts 4 and 5 to prepare exercises. Representing learning objects with our model enables the reuse of objects according to how they have previously been integrated in a scenario.

\section{Conclusions}

The proposed model can be applied to any electronic document which has an educational objective. It can be integrated into any model of learning (synchronous or asynchronous distance learning...). It also presents the possible use and adaptation for any type of course because it was not conceived within the framework of a specific training.

The model is based on a multi-facet representation of documents by using three ontologies: ontology of theme, ontology of the tasks, ontology of the educational theories and a LOM/SCORM description. The proposed ontologies are represented in OWL (Web Ontology Language) (W3C, 2004) and based on the syntax RDF (Resource Description Framework) / XML. OWL makes it possible to explicitly represent the meaning of the terms of vocabularies (labels and concepts) and the relations between the associated concepts.

One of the key points of the model is that the ontologies enable all of the life cycle of a learning object to be covered: from its conception by the teacher to the search for pieces of information on a given notion by learners. It makes it possible to develop a system that helps the designers of learning objects and lessons. The different actors of the system (teachers, learners) and their various tasks are considered. The model includes the flexibility of a semantic representation and search for relevant learning objects by the use of the LOM application profiles. Complying with the standards of on-line courses guarantees interoperability with other systems.

To further our study we intend to set up a system allowing, on the one hand, automatic indexing of learning objects and, on the other hand, searching for learning objects matching a need (expressed by a learner or a teacher). The mechanisms will be based on the theme ontology. The first aspect will be based on the work of Hernandez (2005) who proposed this type of mechanism in another context (scientific documents). Another aspect relates to the automated construction of theme ontologies which must be produced for each domain of teaching. Work of the IRIT laboratory in this field (Aussenac et al., 2000) could be reinvested here.

\section{References}

Abel M.-H., Lenne D., Moulin C., \& Benayache A., (2003). Gestion des ressources pédagogiques d'une eformation [Pedagogical resources for e-learning]. Document Numérique, 7(1-2), 111-128.

Aussenac-Gilles, N., Biébow, B., \& Szulman, S. (2000). Revisiting ontology design: A method based on corpus analysis. Proceedings of the 12th European Knowledge Acquisition Workshop, 172-188.

Bourda, Y. (2001). Objets pédagogiques, vous avez dit objets pédagogiques? [Learning objects, is that what you said?]. Proceedings of the Gutenberg 39-40 congress, 71-79.

Bourigault, D., \& Fabre, C., (2000). Approche linguistique pour l'analyse syntaxique de corpus [Syntactic analysis of texts using linguistics]. Cahiers de Grammaires, 25, 131-151.

Boutemedjet, S. (2004). Web Sémantique et e-Learning, [Semantic web and e-learning] Cours IFT6261. Retrieved from http://www.iro.umontreal.ca/ aimeur/cours/ift6261/Presentationsetudiants/WebSemantiqueE-learning.pdf

Bouzeghoub, A., Defude, B., Duitama, J. F., \& Lecocq, C. (2005). Un modèle de description sémantique de ressources pédagogiques basé sur une ontologie de domaine [A model to describe semantically peda- 
gogical resources using a domain ontology]. Sciences et Technologies de l'Information et de la Communication pour l'Éducation et la Formation (Sticef), 12(13).

De La Passardière, B., \& Jarraud, P. (2004). ManUeL, un profil d'application du LOM pour C@mpuSciences, [ManUel, a LOM application profile for C@mpSciences]. Sciences et Technologies de l'Information et de la Communication pour l'Éducation et la Formation (Sticef), 11, 11-57.

Duval, E., Sutton, S. \& Weibel, S. L. (2002). Metadata Principles and Practicalities. D-Lib Magazine, 8(4). ISSN 1082-9873. Retrieved from http://www.dlib.org/dlib/april02/weibel/04weibel.html

E-TUD [Encyclopedia of Education]. (n.d.). E-learning. Retrieved from http://www.e-tud.com/encyclo_elearning.htm

Fage, C. (2005). Vous avez dit SCORM [You said SCORM]. eLearning Agency, 1-14.

Friesen, N. (2005). Interoperability and Learning Objects: An Overview of E-Learning Standardization. Interdisciplinary Journal of Knowledge and Learning Objects, 1, 23-31. Retrieved from http://ijklo.org/Volume1/v1p023-031Friesen.pdf

Gasevic, D. \& Hatala, M. (2005). Searching context relevant learning resource using ontology mappings. Proceedings of the Intenational.Workshop on Applications of Semantic Web Technologies for Elearning. Retrieved from www.win.tue.nl/SW-EL/2005/swel05-kcap05/proceedings

Hernandez, N. (2005). Ontologies de domaine pour la modélisation du contexte en Recherche d'Information [Domain ontologies for context modeling in Information Retrieval]. Thèse de doctorat [Doctoral thesis]. Université Paul Sabatier.

Hodgins, W. (Chair), (2008). Working group information, announcements \& news. WG12: Learning Object Metadata. Retrieved from http://ltsc.ieee.org/wg12/

IMS Global Learning Consortium. (2003). Learning design specification. Retrieved from http://www.imsglobal.org/learningdesign/

Knight, C., Gasevic, D. \& Richards, G. (2005). Ontologies to integrate learning design and learning content. Journal of Interactive Media in Education, 7. ISSN:1365-893X. Retrieved from http://www-jime.open.ac.uk/2005/07/

Koper, R. (2001). EML-OUNL (Open University of the Netherlands' Educational Modeling Language). Modeling units of study from a pedagogical perspective. Retrieved from http://eml.ou.nl/introduction/docs/ped-metamodel.pdf

Lebrun, M. (2002). Des technologies pour enseigner et apprendre [Technologies to teach and learn]. De Boeck Editor, ISBN 2-8041-3155-6.

Lenne, D., Abel, M.-H., Moulin, C. \& Benayache, A. (2005). Mémoire de formation et apprentissage. [Teaching and Learning]. Proceedings of Environnements Informatiques pour l'Apprentissage Humain (EIAH 2005), Montpellier, 105-116.

LOM. (2002). LOM standard. Document IEEE 1484.12.1-2002.

Mitrovic, A., \& Devedzic, V. (2002). A model of multitutor ontology-based learning environments. Proceedings of the International Conference on Computers in Education, 1557-1558.

Mizoguchi, R. (2004). Le rôle de l'ingénierie ontologique dans le domaine des EIAH, [The role of ontological engineering in the domain of EIAH]. Sciences et Technologies de l'Information et de la Communication pour l'Éducation et la Formation (Sticef), 11. (Numéro spécial : Ontologies pour les EIAH).

Mothe, J., \& Hernandez, N. (2007). Mining thesaurus and texts to build and update a domain ontology. In H. O. Nigro, S. G. C. Císaro, \& D. Xodo (Eds.), Data Mining with Ontologies: Implementations, Findings, and Frameworks (Chap. VII, pp. 123-144). IGI Global.

Psyché, V., Bourdeau, J., Nkambou, R. \& Mizoguchi, R. (2005). Making learning design standards work with an ontology of educational theories. Artificial Intelligence in Education (AIED 2005), 725-731. 
Renaud, S., Vignaux, G., \& Tijus, C. (2005). La commande sémantique: Une navigation conceptuelle pour le cartable électronique [The semantic order: Conceptual browsing for e-portfolio]. Proceedings of the Colloque international sur le document électronique (CIDE06), 133-147.

Robertson, S., \& Sparck Jones, K. (1976). Relevance weighting of search terms. Journal of the American Society for Information Science, 27, 129-146.

SCORM. (2004). Le modèle SCORM [The SCORM model]. Retrieved from http://www.adlnet.org

Snae, C., \& Brueckner, M. (2007). Ontology-driven e-learning system based on roles and activities for Thai learning environment. Interdisciplinary Journal of Knowledge and Learning Objects, 3, 1-17. Retrieved from http://ijklo.org/Volume3/IJKLOv3p001-017Snae.pdf

Stanford Medical Informatics. (2007). Protégé. Retrieved from http://protege.stanford.edu

Studer, R., Benjamins, V. R. \& Fensel, D. (1998). Knowledge engineering: Principles and methods. Data and Knowledge Engineering (DKE), 25(1-2), 161-197.

Varlamis, I., \& Apostolakis, I. (2006). The present and future of standards for e-learning technologies. Interdisciplinary Journal of Knowledge and Learning Objects, 2, 59-76. Retrieved from http://ijklo.org/Volume2/v2p059-076Varlamis.pdf

Vidal, P., Broisin, J., Duval, E, \& Ternier, S. (2004). Normalisation et standardisation des objets d'apprentissages: L'expérience ARIADNE, [Standards for e-learning objects: ARIADNE]. Proceedings of the Colloque " miage et e-mi@ge », ESG, 48-64.

W3C Consortium. (2004). OWL Specification Development. Retrieved from http://www.w3.org/2004/OWL/

Zarraonandía, T., Dodero, J.-M., Díaz, P., \& Sarasa, A. (2004). Domain ontologies integration into the learning objects annotation process. Proceedings of the Workshop on Applications of Semantic Web Technologies for e-Learning, 34-39.

\section{Biographies}

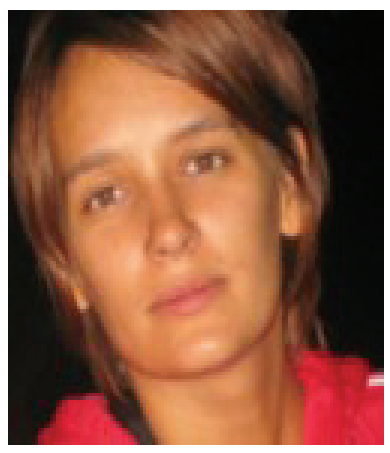

Nathalie Hernandez $(\mathrm{PhD})$ is an assistant professor. She teaches at the Toulouse II University.

She is currently working in the field of the semantic web, in particular on ontology elaboration and use for document indexing and retrieving.

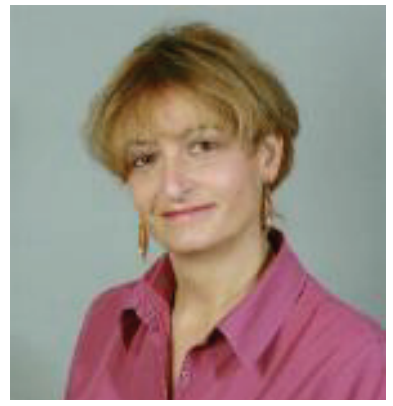

Josiane Mothe $(\mathrm{PhD})$ is professor at the teacher training school of Midi-Pyrénées (IUFM - Institut Universitaire de Formation des Maîtres), université de Toulouse since 2002.

Co-leader of the Information Retrieval - Information Mining and Visualisation group at IRIT and of the ERT hypermedia and e-learning group at IUFM.

She works on information retrieval and text mining; http://www.irit.fr/ Josiane.Mothe 


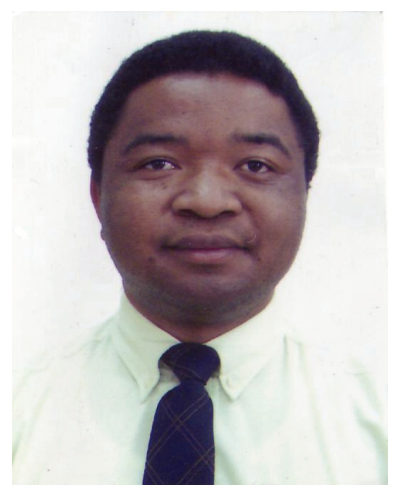

No photo available
Bachelin Ralalason, Ph.D. student, received his M.S. degree from Paul Sabatier University in 2006.

He joined the IRIT (Institut de Recherche en Informatique de Toulouse) in 2005. He works in e-learning, semantic web and personalization. He is also interested in Braille score processing.

Bertin Ramamonjisoa $(\mathrm{PhD})$ is professor and head of the Ecole Nationale d'Informatique de Fianarantsoa in Madagascar.

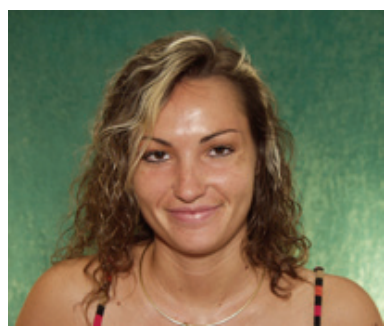

Patricia Stolf $(\mathrm{PhD})$ is an assistant professor. She teaches in IUFM (Institut Universitaire de Formation des Maitres) in Toulouse. She is involved in the training of the teachers (integration of the new technologies in practise) as well as in the distance training (elearning). 